\title{
The association between depression and esophageal cancer in China: a multicentre population-based study
}

\author{
Juan Zhu ${ }^{1 \dagger}$, Shanrui Ma ${ }^{1 \dagger}$, Yueyue Zhou ${ }^{2}$, Ru Chen ${ }^{1}$, Shuanghua Xie ${ }^{1}$, Zhengkui Liư ${ }^{2}$, Xinging Li ${ }^{1}$ and \\ Wenqiang $\mathrm{Wei}^{1^{*}}$
}

\begin{abstract}
Background: Esophageal cancer (EC) is one of the leading contributors to the global burden of cancer, and the underlying mechanism is still unknown. Recently, there has been a growing interest in understanding modifiable psychosocial risk factors, particularly depression, to prevent EC and reduce morbidity and mortality. However, related research is sparse and has been ignored. The study was designed to assess the association between depression and EC in China.
\end{abstract}

Methods: From 2017 to 2019, a population-based multicenter study was conducted in high-risk regions of EC. Participants underwent a free endoscopy screening. If the endoscopic results were suspicious, a pathological biopsy was applied to confirm. Depression was measured with Patient Health Questionnaire-9 (PHQ-9). In addition, information on demographic characteristics and risk factors was collected from participants by trained interviewers using uniform questionnaires.

Results: After Endoscopy and pathologic diagnosis, 15,936 participants in high-risk regions of EC (ECHRRs) were enrolled, 10,907 (68.44\%) of which were diagnosed health, 4048 (25.40\%) with esophagitis, 769 (4.83\%) with lowgrade intraepithelial neoplasia (LGIN), 157 (0.99\%) with high-grade intraepithelial neoplasia (HGIN), and $55(0.35 \%)$ with EC, respectively. The overall prevalence of depression symptoms of participants was $4.16 \%$ (health: 4.63\%, esophagitis: 2.99\%, LGIN: 2.99\%, HGIN: 5.73\%, and EC: 9.09\%). Multiple logistic regression analyses revealed that the unadjusted OR $(95 \% \mathrm{Cl})$ between depression and each esophageal pathology grades were esophagitis 0.93 (0.920.95), LGIN 0.97 (0.94-0.99), HGIN 1.05 (1.00-1.10), and EC 1.04 (0.97-1.14), respectively. However, after adjustment for potential confounders (age, gender, region, alcohol consumption, BMI), no statistically significant associations between depression and $\mathrm{EC}$ (adjusted $\mathrm{OR}=1.10,0.99-1.21$ ) and esophageal lesions (esophagitis: adjusted $\mathrm{OR}=1.02$, 0.99-1.04; LGIN: adjusted $\mathrm{OR}=0.98,0.95-1.01 ; \mathrm{HGIN}$ : adjusted $\mathrm{OR}=1.04,0.98-1.11$ ) were observed in this study.

Conclusions: No significant association was observed between depression and EC in the study. Future prospective cohort studies are needed to verify this preliminary finding.

Keywords: Esophageal cancer, Depression, PHQ-9, Endoscopy, High-risk regions

\footnotetext{
* Correspondence: weiwq@cicams.ac.cn

†Juan Zhu and Shanrui Ma contributed equally to this work.

'National Central Cancer Registry, National Cancer Center / National Clinical Research Center for Cancer / Cancer Hospital, Chinese Academy of Medical Sciences and Peking Union Medical College, Beijing 100021, China Full list of author information is available at the end of the article
} 


\section{Background}

Esophageal cancer (EC) is one of the most prevalent malignancies with high mortality and increasing incidence $[1,2]$. In 2015, the incidence and mortality of EC in China were 17.9 per 100,000 and 13.7 per 100,000 [3, 4]. One-half of new cases occur in China, imposing a heavy economic burden and mental stress on families and society [3-5]. Like most common malignant tumors, EC is a complex disease with multifactorial etiology. Both genetic and environmental factors influence the risk of developing the disease [6-10]. In the past, most etiological studies of EC focused on biology, and social or psychological factors were easily ignored [11-14].

Growing evidence has shown that depression may exert an etiologic role in cancer [15-19]. A recent meta-analysis of 51 prospective studies showed that depression and anxiety disorders could cause a significant 13\% increase in cancer risk and a $21 \%$ increase in cancer-specific mortality [20]. Evidence associated with depression and cancer indicated an increased cancer risk in individuals with depression [21-23]. However, many previous studies on depression and cancer have primarily focused on breast, lung, colorectal cancers [21, 22]. Only a few studies have explored the relationship between depression and ECspecific risk. A meta-analysis reviewing depression and anxiety concerning cancer incidence and mortality covered 21 common tumors [20], but a recent meta-analysis found that only one study concerned depression and the risk of esophageal cancer [24]. The evidence of which was still insufficient. Therefore, a population-based, multicenter study was implemented to estimate the status of depression in high-risk regions of the EC (ECHRRs) and evaluate the association between depression and EC, aimed to provide clues for preliminary screening and prevention of EC and fill the gap in this field.

\section{Methods}

\section{Study design}

The national cohort of esophageal cancer (NCEC) is a multi-center prospective cohort study of EC and precancerous lesions based on high-risk populations in China [25]. Details on the cohort have already been published [25]. This study is based on the NCEC cohort and provided free gastroscopy screening services for upper gastrointestinal tumors to residents aged 40 to 69 years in five ECHRRs (Linzhou, Henan; Cixian, Hebei; Feicheng, Shandong; Yangzhong, Jiangsu; Yanting, Sichuan) from May 2017 to November 2019 (Fig. 1). All participants were recruited and interviewed face-to-face by trained staff. A uniform questionnaire was used to collect their basic information, including living and eating habits, disease history, family tumor history, and other exposure factors. Then, eligible participants received an upper gastrointestinal endoscopy examination. If an endoscopy detects suspicious esophageal lesions, esophageal pathology would be applied to confirm clinical health, esophagitis, low-grade intraepithelial neoplasia (LGIN), high-grade intraepithelial neoplasia (HGIN), and EC. The details related to the design of the NCEC are described on the website (http://www.ncec-China.cn/ cmmct.html) and elsewhere [25].

\section{Study participants}

The inclusion criteria included: (a) residents aged 40-69 years old; (b) no severe vision or hearing problems; (c) be able to comprehend the survey process properly; and (d) being competent to provide written informed consent. The exclusion criteria included: (a) previous diagnosis of EC or other cancers and (b) being contraindications for endoscopic examinations (e.g., acute perforation of the upper digestive tract, severe heart, lung, kidney, brain dysfunction, and multi-organ failure).

\section{Instruments}

Before the esophageal endoscopy examination, all depression surveys were conducted using the Chinese version of the Patient Health Questionnaire-9 (PHQ-9). The PHQ-9 is a self-reported questionnaire assessing the presence and severity of depression with good test-retest reliability and good validity in primary medical care and clinical practice [26, 27].

PHQ-9 consists of 9 items (anhedonia, depressed mood, sleep problems, fatigue, weight/appetite change, feelings of worthlessness/guilt, poor concentration, psychomotor retardation/agitation, thoughts of self-harm/ suicidal ideations) that are based directly on the nine diagnostic criteria for major depression in the Diagnostic and Statistical Manual of Mental Disorders, Fifth Edition (DSM-V) [28]. PHQ-9 has 4 response scores representing the frequency of each depressive symptom in the past 2 weeks ( $0=$ "not at all", $1=$ "several days", 2 = "more than half the days", and 3 = "nearly every day"). The depression score was the total of each item from 0 to 27. A higher depression score indicates severe depression. Depression score is also used as a binary variable: cutoff score at 7, meaning 7 or above is depressive [29].

\section{Covariate variables}

Based on the results of face-to-face interviews and a comprehensive literature review. The following covariates were included in the study: age ( $\leq 50 \mathrm{y}, 51-60 \mathrm{y}$, $>60 y$ ), gender, region, alcohol consumption [30, 31], and body mass index (BMI) [32-36]. Alcohol consumption was used to evaluate the frequency of drinking in the past year, divided into never (or almost never), only occasionally, most days (or almost every day). Additionally, both weight and height were measured on the 


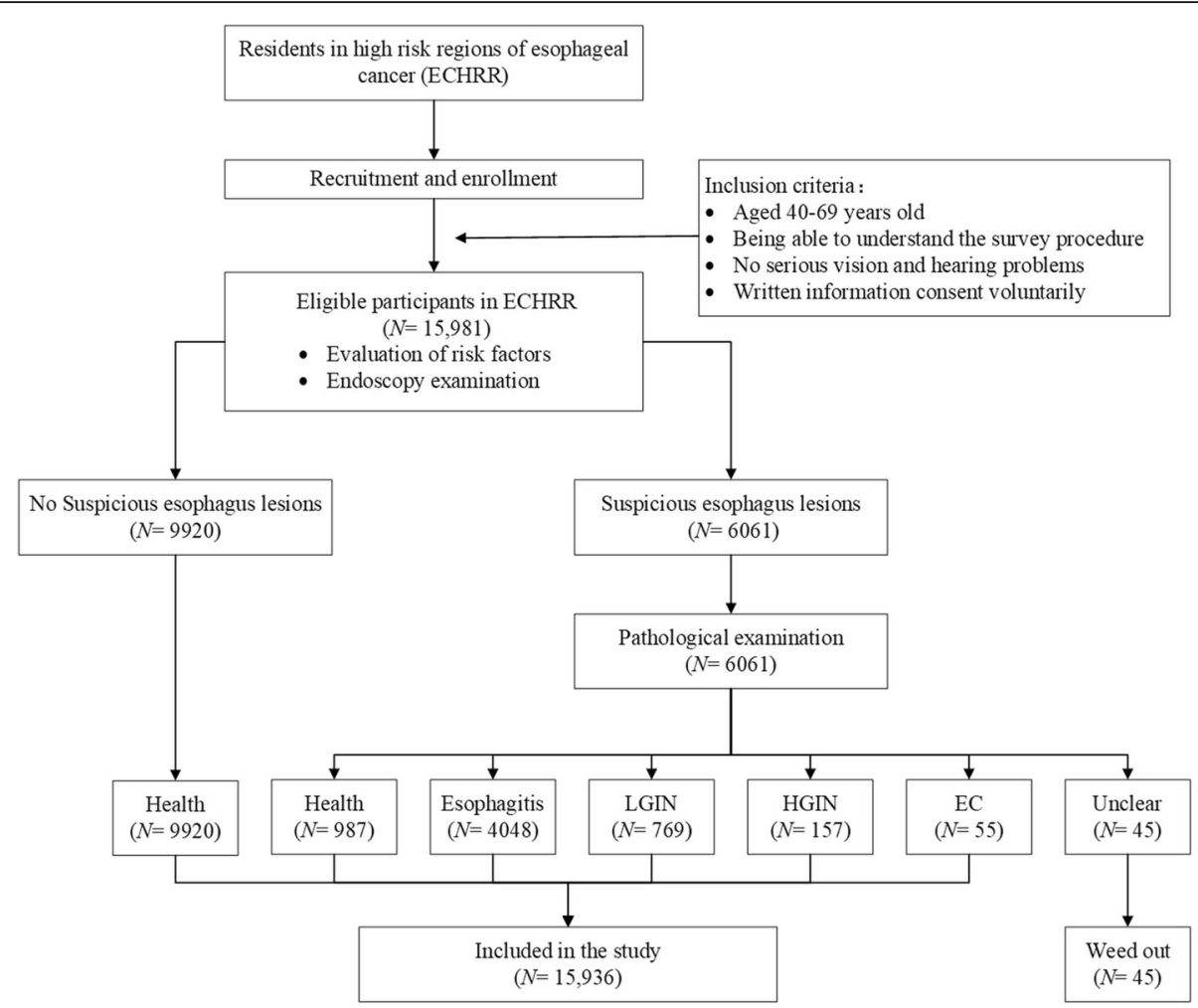

Fig. 1 The flowchart of the study. Training staff interviewed eligible participants via a uniform and laptop-based questionnaire to collect information on their exposure to risk factors (psychological information included) $(N=15,981)$. An esophageal endoscopy examination would be performed after the questionnaire $(N=15,981)$. If esophageal endoscopy results were suspicious $(N=6061)$, a pathological biopsy would be further conducted $(N=6061)$. Screeners were diagnosed as health $(N=987)$, esophagitis $(N=4048)$, low-grade intraepithelial neoplasia (LGIN) $(N=769)$, high-grade intraepithelial neoplasia (HGIN) $(N=157)$, esophageal cancer $(E C)(N=55)$, and unclear $(N=45)$

endoscopy examination day, BMI was calculated as the weight in kilograms divided by the square of the height in meters $\left(\mathrm{kg} / \mathrm{m}^{2}\right)$, and classified according to the World Health Organization (WHO) guidelines: underweight: < 18.5 , normal $\geq 18.5$ and $<25$, overweight $\geq 25$ and $<30$, and obese $\geq 30$.

\section{Statistics}

SAS version is 9.4 statistical programs (SAS Institute, Cary, NC) was used for data management and analyses. The continuous and qualitative variables were summarized as mean \pm standard deviation (SD) or median with the first and third quartile (Q1-Q3) and frequency (\%), respectively. We used the Student's t-test for normally distributed variables and Kruskal-Wallis for non-parametric variables to analyze the continuous data. Categorical variables were compared using Chi-square or Fisher's exact test. Multiple linear regression models (stepwise) were performed to test for correlation between covariates before covariate modeling. Collinearity diagnostics using the variance inflation factor (VIF) showed no evidence of collinearity among covariates (VIF < 10.0) [37]. Finally, we performed multivariable-adjusted logistic regressions to determine the association between depression (PHQ-9 scores) and different esophageal lesions. Specifically, model 1 was non-adjusted that estimated the raw contribution of depression to the prediction of esophageal lesions; model 2 was adjusted for age, gender, and region; model 3 was adjusted for age, gender, region, alcohol, and BMI. All tests of significance were two-tailed, and $P<0.05$ was examined statistically significant.

\section{Ethics statement}

The study was performed in accordance with the institutional research ethics guidelines and the Helsinki declaration. Formal ethics approval was granted by the Ethics Committee of Cancer Institute and Hospital, Chinese Academy of Medical Sciences (No.16-171/1250). All the participants were informed about the purpose of the study and provided written informed consent.

\section{Results}

The screening detection and diagnosis of different esophageal lesions

As showed in Fig. 1, A total of 15,981 eligible participants were enrolled in five ECHRRs. After endoscopy 
and pathologic diagnosis, 15,936 participants were entered in the present study, as 45 participants had an unclear pathological diagnosis. And 10,907 health (68.44\%), 4048 esophagitis (25.40\%), 769 LGIN (4.83\%), 157 HGIN $(0.99 \%)$ and 55 EC (0.35\%) cases were confirmed, respectively.

\section{Baseline characteristics of participants with different esophageal lesions}

The baseline characteristics of participants are shown in Table 1. The mean age of all participants was $(55.44 \pm$ 7.74) years. Healthy people are younger than others $(P<$ $0.001)$. Over half of the participants $(58.56 \%)$ were women, while the HGIN and EC group included more males patients (50.32, 56.36\%). Moreover, the differences in baseline characteristics between the healthy group and the other esophageal lesions groups were statistically significant in terms of region, marital status, highest education level, occupation, household income, smoking status, alcohol and tea consumption, physical activities, life satisfaction status, self-rated health status, and BMI (all $P<0.05$ ).

\section{The depression symptoms of participants with esophageal lesions}

As showed in Table 2, the overall prevalence of depression (PHQ-9 $>7$ ) in the study was $4.16 \%(663 / 15,936)$. The corresponding prevalence of depression of participants diagnosed with health, esophagitis, LGIN, HGIN, and EC were $4.63 \%(505 / 10,907), 2.99 \%$ (121/4048), $2.99 \%$ (23/769), 5.73\% (9/157), and 9.09\% (5/55), respectively $(P<0.001)$. The significant variations in depression among the different demographic characteristics and life habits such as region $(P<0.001)$, the highest education level $(P=0.021)$, occupation $(P<0.001)$, household income $(P=0.006)$, alcohol consumption $(P<0.001)$, tea consumption $(P<0.001)$, physical activities $(P<0.001)$, life satisfaction status $(P<0.001)$, self-rated health status $(P<0.001)$, and BMI $(P=0.010)$.

\section{Multiple linear regression analysis of depression (PHQ-9 scores) and baseline characteristics}

Table 3 shows the regression equation results by multiple linear regression analysis (forward stepwise selection method). Depression (PHQ-9 score as dependent variable) is related to occupation, life satisfaction status, region, household income, physical activities, self-rated health status, tea consumption, BMI, alcohol consumption, marital status, highest education level. The results of collinearity diagnostics showed that all VIF values were below 10, which indicated that no severe multicollinearities exist between the independent variables in this study.

\section{The association between depression and the esophageal} lesions

Afterward, we performed a multiple logistics regression analysis to explore the relationships between depression (PHQ-9 scores) and different esophageal lesions (Table 4). Compared with healthy participants (reference), the unadjusted OR (95\% CIs) between depression and each grade of esophageal pathology were 0.93 (0.92-0.95), 0.97 (0.94$0.99), 1.05$ (1.00-1.10), and 1.04 (0.97-1.14), respectively. After further adjustment for the age, gender, region, alcohol consumption, and BMI, depression has not shown a significant association with all esophageal pathology. The corresponding OR $(95 \% \mathrm{CI})$ of the associations were 1.02 (0.99-1.04), 0.98 (0.95-1.01), 1.04 (0.98-1.11), and 1.10 (0.99-1.21), respectively.

\section{Discussion}

With the transition from a biological medical model to a biopsychosocial model, the impact of psychosocial factors on cancer progression has attracted much attention. This study is the first to focus on depression symptoms and esophageal lesions in a large-scale multi-center population on a global scale, which filled the gap in this field. Findings from this population-based study supported the view that the prevalence of depression in ECHRRs was high, especially for EC. Nevertheless, we found no evidence of an association between depression and the risk of either esophageal lesions or EC.

Depression is among the most prevalent and disabling psychological disorders worldwide and affects 350 million people [38-40]. Evidence from the China Kadoorie Biobank (CKB) study of 0.5 million adults indicated that depression could not be ignored in China [41]. The latest National Health Survey (NHS) in 2019 reported that the lifetime prevalence of depressive disorders was $6.8 \%$ in China [42]. In our study, the overall prevalence of depression in ECHRRs was 4.16\%, participants with EC was $9.09 \%$, which was higher than the national level. The possible explanation is that EC is one of the most human malignant tumors, with high mortality and poor survival $[2,3]$, threatening the health of people living in ECHRRs. Residents have a higher risk of EC and suffer higher stress and anxiety, prioritizing those under limited psychological health resources.

Interestingly, the prevalence of depression was lower in patients with esophagitis and LGNI than health in our study. A possible reason was that the study was carried out in screening populations instead of clinical medical records, so most screening participants were healthy people. It indicated that the healthy people had strong health awareness on cancer screening, paid much attention to their body, and even worry about their health, which may lead to a high level of depressive disorders. The second explanation was that patients with 


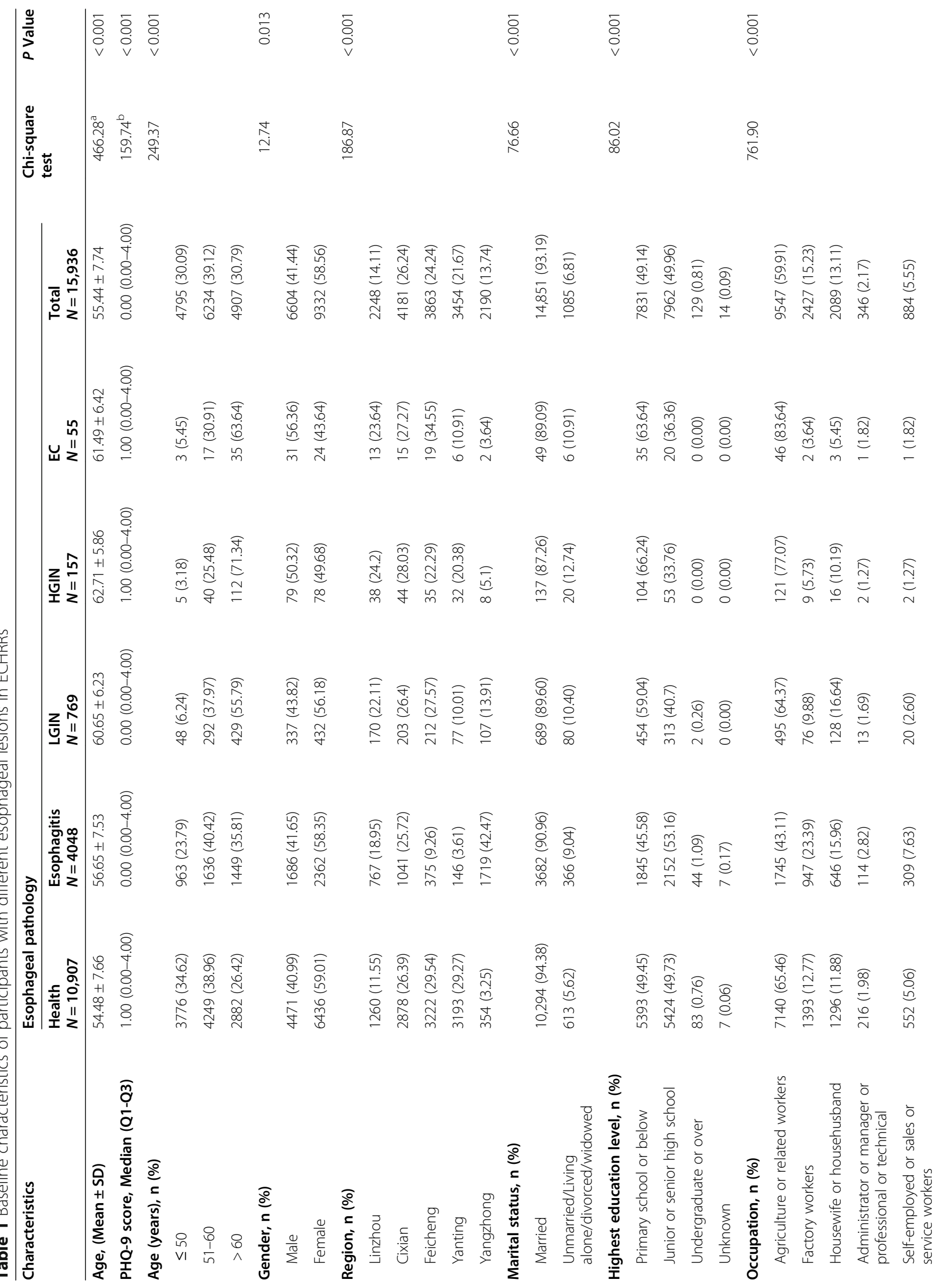




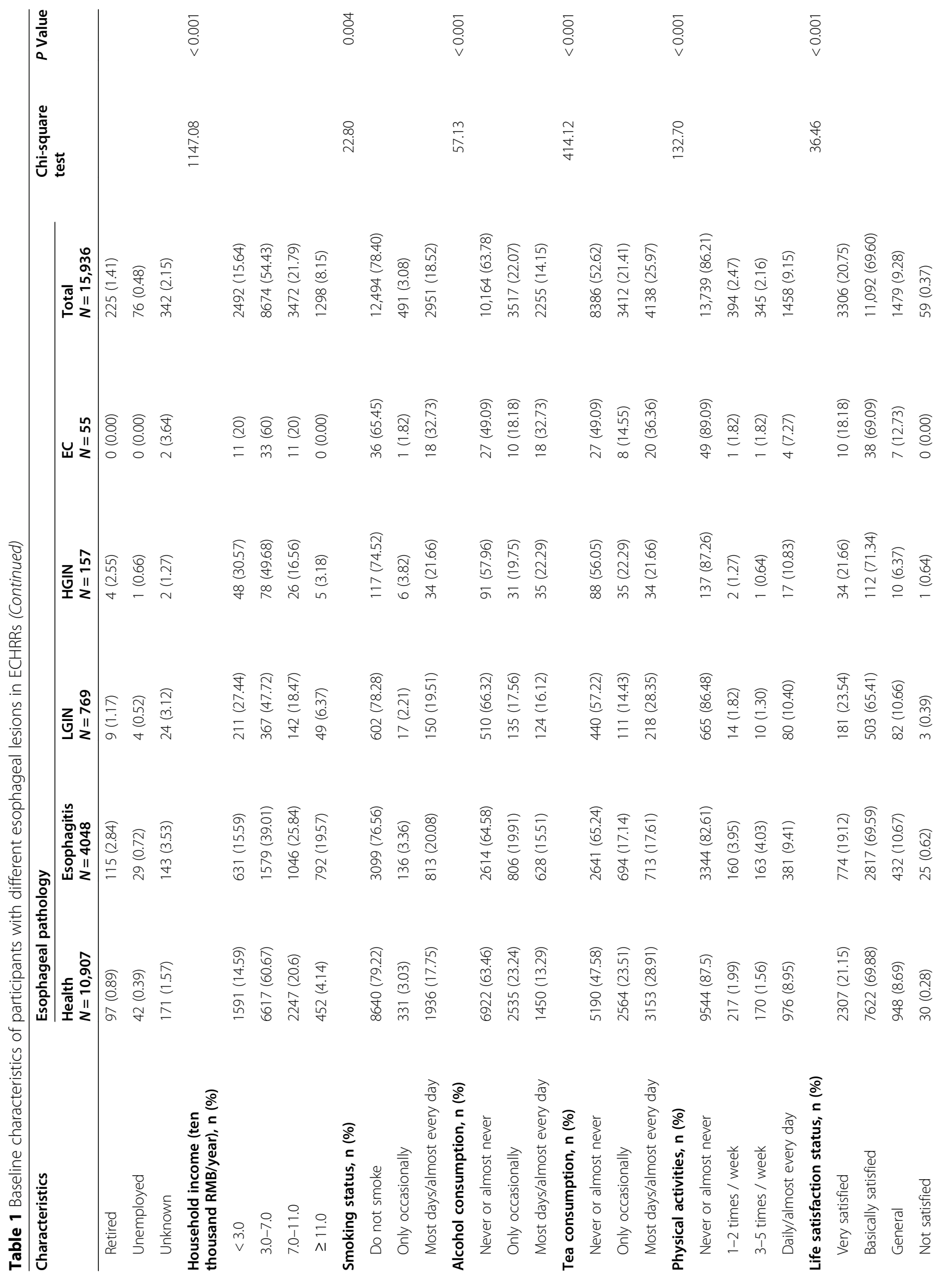




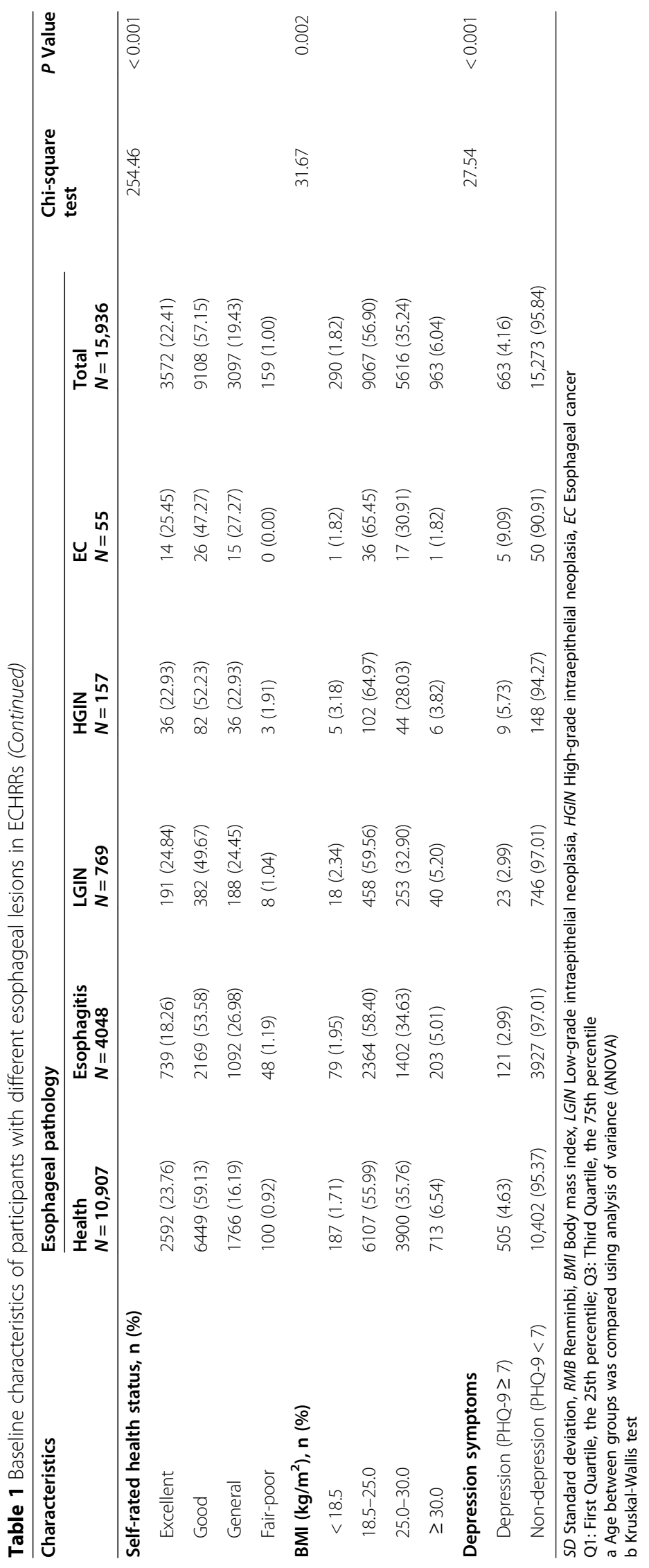


Table 2 Baseline characteristics of participants with depression symptoms in ECHRRs

\begin{tabular}{|c|c|c|c|c|c|c|c|c|}
\hline \multirow[t]{2}{*}{ Characteristics } & \multicolumn{2}{|c|}{ Depression } & \multicolumn{2}{|c|}{ Non-depression } & \multicolumn{2}{|l|}{ Total } & \multirow{2}{*}{$\begin{array}{l}\text { Chi-square } \\
\text { test }\end{array}$} & \multirow[t]{2}{*}{$P$ Value } \\
\hline & $n=663$ & $\%$ & $n=15,273$ & $\%$ & $n=15,936$ & $\%$ & & \\
\hline Age (Mean \pm SD) & $55.45 \pm 7$ & & $55.44 \pm 7.75$ & & $55.44 \pm 7.74$ & & $-0.047^{\mathrm{a}}$ & 0.963 \\
\hline Age (years) & & & & & & & 0.29 & 0.867 \\
\hline$\leq 50$ & 194 & 29.26 & 4601 & 30.13 & 4795 & 30.09 & & \\
\hline $51-60$ & 265 & 39.97 & 5969 & 39.08 & 6234 & 39.12 & & \\
\hline$>60$ & 204 & 30.77 & 4703 & 30.79 & 4907 & 30.79 & & \\
\hline Gender & & & & & & & 0.30 & 0.587 \\
\hline Male & 268 & 40.42 & 6336 & 41.48 & 6604 & 41.44 & & \\
\hline Female & 395 & 59.58 & 8937 & 58.52 & 9332 & 58.56 & & \\
\hline Region & & & & & & & 181.80 & $<0.001$ \\
\hline Linzhou & 70 & 10.56 & 2178 & 14.26 & 2248 & 14.11 & & \\
\hline Cixian & 217 & 32.73 & 3964 & 25.95 & 4181 & 26.24 & & \\
\hline Feicheng & 94 & 14.18 & 3769 & 24.68 & 3863 & 24.24 & & \\
\hline Yanting & 253 & 38.16 & 3201 & 20.96 & 3454 & 21.67 & & \\
\hline Yangzhong & 29 & 4.37 & 2161 & 14.15 & 2190 & 13.74 & & \\
\hline Marital status & & & & & & & 1.64 & 0.200 \\
\hline Married & 626 & 94.42 & 14,225 & 93.14 & 14,851 & 93.19 & & \\
\hline Unmarried/Living alone/divorced/widowed & 37 & 5.58 & 1048 & 6.86 & 1085 & 6.81 & & \\
\hline Highest education level & & & & & & & 9.78 & 0.021 \\
\hline Primary school or below & 350 & 52.79 & 7481 & 48.98 & 7831 & 49.14 & & \\
\hline Junior or senior high school & 304 & 45.85 & 7658 & 50.14 & 7962 & 49.96 & & \\
\hline Undergraduate or over & 6 & 0.90 & 123 & 0.81 & 129 & 0.81 & & \\
\hline Unknown & 3 & 0.45 & 11 & 0.07 & 14 & 0.09 & & \\
\hline Occupation & & & & & & & 111.59 & $<0.001$ \\
\hline Agriculture or related workers & 519 & 78.28 & 9028 & 59.11 & 9547 & 59.91 & & \\
\hline Factory workers & 44 & 6.64 & 2383 & 15.60 & 2427 & 15.23 & & \\
\hline Housewife or househusband & 56 & 8.45 & 2033 & 13.31 & 2089 & 13.11 & & \\
\hline Administrator or manager or professional or technical & 12 & 1.81 & 334 & 2.19 & 346 & 2.17 & & \\
\hline Self-employed or sales or service workers & 17 & 2.56 & 867 & 5.68 & 884 & 5.55 & & \\
\hline Retired & 5 & 0.75 & 220 & 1.44 & 225 & 1.41 & & \\
\hline Unemployed & 2 & 0.30 & 74 & 0.48 & 76 & 0.48 & & \\
\hline Unknown & 8 & 1.21 & 334 & 2.19 & 342 & 2.15 & & \\
\hline Household income (ten thousand RMB/year) & & & & & & & 20.99 & 0.006 \\
\hline$<3.0$ & 85 & 12.82 & 2407 & 15.76 & 2492 & 15.64 & & \\
\hline $3.0-7.0$ & 412 & 62.14 & 8262 & 54.10 & 8674 & 54.43 & & \\
\hline $7.0-11.0$ & 132 & 19.91 & 3340 & 21.87 & 3472 & 21.79 & & \\
\hline$\geq 11.0$ & 34 & 5.13 & 1264 & 8.28 & 1298 & 8.15 & & \\
\hline Smoking status & & & & & & & 0.88 & 0.644 \\
\hline Do not smoke & 529 & 79.79 & 11,965 & 78.34 & 12,494 & 78.40 & & \\
\hline Only occasionally & 18 & 2.71 & 473 & 3.10 & 491 & 3.08 & & \\
\hline Most days or almost every day & 116 & 17.50 & 2835 & 18.56 & 2951 & 18.52 & & \\
\hline Alcohol consumption & & & & & & & 57.81 & $<0.001$ \\
\hline Never or almost never & 415 & 62.59 & 9749 & 63.83 & 10,164 & 63.78 & & \\
\hline Only occasionally & 205 & 30.92 & 3312 & 21.69 & 3517 & 22.07 & & \\
\hline
\end{tabular}


Table 2 Baseline characteristics of participants with depression symptoms in ECHRRs (Continued)

\begin{tabular}{|c|c|c|c|c|c|c|c|c|}
\hline \multirow[t]{2}{*}{ Characteristics } & \multicolumn{2}{|c|}{ Depression } & \multicolumn{2}{|c|}{ Non-depression } & \multicolumn{2}{|l|}{ Total } & \multirow{2}{*}{$\begin{array}{l}\text { Chi-square } \\
\text { test }\end{array}$} & \multirow[t]{2}{*}{$P$ Value } \\
\hline & $n=663$ & $\%$ & $n=15,273$ & $\%$ & $n=15,936$ & $\%$ & & \\
\hline Most days or almost every day & 43 & 6.49 & 2212 & 14.48 & 2255 & 14.15 & & \\
\hline Tea consumption & & & & & & & 52.02 & $<0.001$ \\
\hline Never or almost never & 325 & 49.02 & 8061 & 52.78 & 8386 & 52.62 & & \\
\hline Only occasionally & 215 & 32.43 & 3197 & 20.93 & 3412 & 21.41 & & \\
\hline Most days or almost every day & 123 & 18.55 & 4015 & 26.29 & 4138 & 25.97 & & \\
\hline Physical activities & & & & & & & 18.55 & $<0.001$ \\
\hline Never or almost never & 606 & 91.40 & 13,133 & 85.99 & 13,739 & 86.21 & & \\
\hline 1-2 times / week & 9 & 1.36 & 385 & 2.52 & 394 & 2.47 & & \\
\hline 3-5 times / week & 7 & 1.06 & 338 & 2.21 & 345 & 2.16 & & \\
\hline Daily or almost every day & 41 & 6.18 & 1417 & 9.28 & 1458 & 9.15 & & \\
\hline Life satisfaction status & & & & & & & 65.40 & $<0.001$ \\
\hline Very satisfied & 73 & 11.01 & 3233 & 21.17 & 3306 & 20.75 & & \\
\hline Basically satisfied & 482 & 72.70 & 10,610 & 69.47 & 11,092 & 69.60 & & \\
\hline General & 103 & 15.54 & 1376 & 9.01 & 1479 & 9.28 & & \\
\hline Not satisfied & 5 & 0.75 & 54 & 0.35 & 59 & 0.37 & & \\
\hline Self-rated health status & & & & & & & 36.62 & $<0.001$ \\
\hline Excellent & 105 & 15.84 & 3467 & 22.70 & 3572 & 22.41 & & \\
\hline Good & 434 & 65.46 & 8674 & 56.79 & 9108 & 57.15 & & \\
\hline General & 108 & 16.29 & 2989 & 19.57 & 3097 & 19.43 & & \\
\hline Fair-poor & 16 & 2.41 & 143 & 0.94 & 159 & 1.00 & & \\
\hline BMI (kg/m2) & & & & & & & 11.34 & 0.010 \\
\hline$<18.5$ & 14 & 2.11 & 276 & 1.81 & 290 & 1.82 & & \\
\hline $18.5-25.0$ & 409 & 61.69 & 8658 & 56.69 & 9067 & 56.90 & & \\
\hline $25.0-30.0$ & 194 & 29.26 & 5422 & 35.50 & 5616 & 35.24 & & \\
\hline$\geq 30.0$ & 46 & 6.94 & 917 & 6.00 & 963 & 6.04 & & \\
\hline Esophageal pathology & & & & & & & 27.54 & $<0.001$ \\
\hline Health & 505 & 76.17 & 10,402 & 68.11 & 10,907 & 68.44 & & \\
\hline Esophagitis & 121 & 18.25 & 3927 & 25.71 & 4048 & 25.40 & & \\
\hline LGIN & 23 & 3.47 & 746 & 4.88 & 769 & 4.83 & & \\
\hline HGIN & 9 & 1.36 & 148 & 0.97 & 157 & 0.99 & & \\
\hline EC & 5 & 0.75 & 50 & 0.33 & 55 & 0.35 & & \\
\hline
\end{tabular}

SD Standard deviation, RMB Renminbi, BMI Body mass index, LGIN Low-grade intraepithelial neoplasia, HGIN High-grade intraepithelial neoplasia, EC Esophageal cancer

a t test

esophagitis and LGIN have almost no physical discomfort and do not need special treatment and surgery, which would bring little psychological burden. Besides, patients with esophagitis and LGIN maybe feel lucky and glad that they do not have cancer.

Our study found no evidence of an association between depression and the risk of either esophageal lesions or EC. The following factors may explain the observed non-significant association. 1) There is a lack of solid evidence of a positive association between cancer and depression, and the existing epidemiological studies have yielded conflicting results. Several metaanalyses and systematic reviews have been published on the topic but have reported mixed results. More recently, a meta-analysis published in 2007 suggested a small and modestly significant relationship between depression and the risk of cancer incidence (RR 1.13; 95\% CI:1.06-1.19) [20]. However, a meta-analysis found that clinically diagnosed depressive disorder people do not have an elevated risk for cancer incidence (OR 1.15; 95\% CI:0.85-1.56) [43]. So far, the research on the relationship between esophageal cancer and depression is sparse, 
Table 3 Multiple linear regression analysis of depression (PHQ-9 score) and baseline characteristics ${ }^{\text {a }}$

\begin{tabular}{|c|c|c|c|c|c|c|c|}
\hline \multirow[t]{2}{*}{ Characteristics } & \multirow[t]{2}{*}{ Unstandardized $\beta$} & \multirow{2}{*}{$\begin{array}{l}\text { Coefficients } \\
\text { Std.Error }\end{array}$} & \multirow[t]{2}{*}{ Standardized $\beta$} & \multirow[t]{2}{*}{$95 \% \mathrm{Cl}$ for $\beta$} & \multirow{2}{*}{$\begin{array}{l}P \\
\text { value }\end{array}$} & \multicolumn{2}{|c|}{ Collinerity Statistics } \\
\hline & & & & & & Tolerance & VIF \\
\hline Occupation & 0.191 & 0.008 & 0.199 & $(0.176,0.205)$ & $<0.001$ & 0.845 & 1.184 \\
\hline Life satisfaction status & -0.151 & 0.008 & -0.150 & $(-0.167,-0.135)$ & $<0.001$ & 0.794 & 1.260 \\
\hline Region & -0.331 & 0.018 & -0.148 & $(-0.366,-0.297)$ & $<0.001$ & 0.852 & 1.173 \\
\hline Household income & -0.111 & 0.009 & -0.096 & $(-0.128,-0.094)$ & $<0.001$ & 0.934 & 1.071 \\
\hline Physical activities & 0.130 & 0.011 & 0.088 & $(0.108,0.152)$ & $<0.001$ & 0.904 & 1.106 \\
\hline Self-rated health status & -0.073 & 0.008 & -0.073 & $(-0.088,-0.057)$ & $<0.001$ & 0.798 & 1.253 \\
\hline Tea consumption & 0.027 & 0.007 & 0.031 & $(0.013,0.041)$ & $<0.001$ & 0.781 & 1.280 \\
\hline BMI & -0.139 & 0.032 & -0.031 & $(-0.203,-0.075)$ & $<0.001$ & 0.982 & 1.018 \\
\hline Alcohol consumption & 0.022 & 0.007 & 0.025 & $(0.008,0.036)$ & 0.002 & 0.825 & 1.213 \\
\hline Marital status & -0.030 & 0.012 & -0.018 & $(-0.053,-0.006)$ & 0.013 & 0.962 & 1.040 \\
\hline Highest education level & 0.012 & 0.006 & 0.015 & $(0.000,0.024)$ & 0.048 & 0.928 & 1.078 \\
\hline
\end{tabular}

a Adjusted $\mathrm{R}^{2}=0.164$

Dependent Variable: PHQ-9 score

and our findings filled the gap in the field. 2) Although the total screening participants is enough, the HGNI and $\mathrm{EC}$ from the screening population were relatively more minor, which means that related results carry uncertainty to some extent and need to be interpreted cautiously. 3) We tried to put many covariates in modeling regression before, and the results showed a positive association between depression and esophageal cancer. On second consideration, considering that the smallest group only includes 55 people and the possibility of overfitting, we made a priori selection for the current confounding factors, and the results turned out to change from positive correlation to non-significant correlation. Despite our negative results between depression and EC-related diseases, depression must not be ignored because increasing evidence found that depression may be influencing the progression of cancer [15, 16, 44, 45].

Reverse causation may exist between depression and EC because cancer diagnosis could influence the mental health status or rise to depression [46]. Unlike most previous studies, our research evaluated the association of depression and EC in a population and excluded people with a cancer history, minimizing the influence of reverse causality. Furthermore, the results indicated that distress symptoms alone appear to be relatively less harmful to cancer development [43]. Considering that most human cancers have a long latency period and are difficult to detect during the early stages of cancer, an association between depression and EC was not identified in this cross-sectional study. In addition, lifestyle and behavioral changes may influence the association between depression and cancer indirectly. People with depression are more likely to have unhealthy lifestyle habits [47]. For instance, according to Watts, most individuals with depressive disorders abuse alcohol in search of disinhibition or reduce emotional and behavioral symptoms of depression [48]. Obesity and BMI were associated with depression $[49,50]$. In this cross-sectional study, the ratio of depression differed according to regions, education level, occupation, alcohol drinking habit, and BMI level. However, risk factors of depression and EC are in part shared, further complicating causal interpretations. Among those, socioeconomic status (SES), education level may play mediating roles in the

Table 4 Odds ratios (OR) of association between depression symptoms and esophageal lesions in ECHRRs

\begin{tabular}{|c|c|c|c|c|c|}
\hline Esophageal pathology & Health & $\begin{array}{l}\text { Esophagitis } \\
\text { OR }(95 \% \mathrm{Cl})\end{array}$ & $\begin{array}{l}\text { LGIN } \\
\text { OR }(95 \% \mathrm{Cl})\end{array}$ & $\begin{array}{l}\text { HGIN } \\
\text { OR }(95 \% C l)\end{array}$ & $\begin{array}{l}\text { EC } \\
\text { OR }(95 \% \mathrm{Cl})\end{array}$ \\
\hline Model $1^{a}$ & Ref & $0.93(0.92-0.95)^{* *}$ & $0.97(0.94-0.99)^{* *}$ & $1.05(1.00-1.10)^{*}$ & $1.04(0.97-1.14)$ \\
\hline Model $2^{\mathrm{b}}$ & Ref & $1.01(0.99-1.03)$ & $0.97(0.94-1.01)$ & $1.04(0.98-1.11)$ & $1.08(0.98-1.19)$ \\
\hline Model $3^{c}$ & Ref & $1.02(0.99-1.04)$ & $0.98(0.95-1.01)$ & $1.04(0.98-1.11)$ & $1.10(0.99-1.21)$ \\
\hline
\end{tabular}

OR Odds ratio, 95\% Cl 95\% Confidence interval, LGIN Low-grade intraepithelial neoplasia, HGIN High-grade intraepithelial neoplasia, EC Esophageal cancer,

a Model 1: Univariate model including depression (depression was used as a continuous variable)

b Model 2: Model $1+$ age + gender + region

c Model 3: Model $2+$ alcohol consumption + BMI

* $P<0.05 ;{ }^{*} P<0.01$ 
association between depression and EC. Intermediary factor analysis will be taken into account in further study.

Several limitations to this pilot study have to be acknowledged. First, due to the study's cross-sectional design, causal inferences cannot be shown, and the long-term effects of depression on EC progression are also unavailable. Second, volunteer bias may exist. Residents were willing to participate in the endoscopy program actively because of free. Third, even though we try to control the confounding factors as much as possible, the smallest group only included 55 persons; we do not have the correct number of participants to include more covariables. Therefore, we cannot control the confounding factors completely. Finally, the results in ECHRRs may not be generalization to the general population, which should be interpreted with caution.

\section{Conclusion}

Our study took the lead in investigating the association between depression and EC in China. Findings from this population-based study supported the view that the prevalence of depression in ECHRRs was high. There is no clear evidence that depression may be a contributing factor to EC and precancerous lesions. The results should be interpreted with caution.

\section{Implications}

Depression, causing a significant psychological burden, has long been underestimated seriously worldwide. Confronted with a lack of awareness of the psychological health of Chinese people, and there is a considerable gap in psychological services between China and developed counties. The government in China is actively promoting improving residents' mental health literacy to $30 \%$ by 2030. The priorities of psychological health resources should be provided to high-risk populations, such as residents in ECHRRs and people screened to HGIN and EC.

\section{Abbreviations}

EC: Esophageal cancer; ECHRRs: high-risk regions of EC; NCEC: The national cohort of esophageal cancer; LGIN: Low-grade intraepithelial neoplasia; HGIN: High-grade intraepithelial neoplasia; PHQ-9: Patient Health Questionnaire-9; HPA: Hypothalamic-pituitary-adrenal axis; CKB: China Kadoorie Biobank; WHO: World Health Organization; NHS: National Health Survey; RMB: Renminbi; BMl: Body mass index

\section{Acknowledgments}

We thank all participants for accepting and completing the interview voluntarily. We thank all those staff of NCEC and provincial sites for their support for the study. We thank all consultant experts for their constructive suggestions for our work.

\section{Authors' contributions}

J.Z and SR.M did the study concept and design, analysis and interpretation of data, drafting the manuscript, and approval of the final draft manuscript.
YY.Z, R.C, and SH.X performed statistical analysis and interpretation of data, and approval of the final draft manuscript. ZK.L, XQ.L, and WQ.W did the critical revision of the manuscript for important intellectual content. All authors agreed to be accountable for the content of the work.

\section{Funding}

The study was supported by the National Science \& Technology Fundamental Resources Investigation Program of China

(2019FY101101) and the National Key Research and Development Program (Precision Medicine Research) (2016YFC0901400, 2016YFC0901404)

\section{Availability of data and materials}

The datasets for this manuscript maybe not publicly available because all our data are under the regulation of the National Cancer Center in China. Requests to access the datasets should be directed to Wenqiang Wei, weiwq@cicams.ac.cn.

\section{Declarations}

Ethics approval and consent to participate

The study was performed in accordance with the institutional research ethics guidelines and the Helsinki declaration. Formal ethics approval was granted by the Ethics Committee of Cancer Institute and Hospital, Chinese Academy of Medical Sciences (No.16-171/1250). All the participants were informed about the purpose of the study and provided written informed consent.

Consent for publication

Not applicable.

\section{Competing interests}

The authors declare that they have no competing interests.

\section{Author details}

${ }^{1}$ National Central Cancer Registry, National Cancer Center / National Clinical Research Center for Cancer / Cancer Hospital, Chinese Academy of Medical Sciences and Peking Union Medical College, Beijing 100021, China. ${ }^{2}$ Key Laboratory of Mental Health, Institute of Psychology, Chinese Academy of Sciences, Beijing 100101, China.

Received: 12 May 2021 Accepted: 11 October 2021

Published online: 10 November 2021

\section{References}

1. Sung $H$, Ferlay J, Siegel RL, Laversanne M, Soerjomataram I, Jemal A, et al. Global Cancer Statistics 2020: GLOBOCAN Estimates of Incidence and Mortality Worldwide for 36 Cancers in 185 Countries. CA Cancer J Clin. 2021; 71(3):209-49. https://doi.org/10.3322/caac.21660.

2. GBD 2017 Oesophageal Cancer Collaborators. The global, regional, and national burden of oesophageal cancer and its attributable risk factors in 195 countries and territories, 1990-2017: a systematic analysis for the Global Burden of Disease Study 2017. Lancet Gastroenterol Hepatol. 2020;5(6):582-97. https://doi.org/10.1016/S24 68-1253(20)30007-8.

3. Chen WQ, Zheng RS, Baade PD, Zhang S, Zeng H, Bray F, et al. Cancer statistics in China, 2015. CA Cancer J Clin. 2016;66(2):115-32. https://doi. org/10.3322/caac.21338.

4. Chen R, Zheng RS, Zhang SW, Zeng HM, Wang SM, Sun KX et al. Analysis of incidence and mortality of esophageal cancer in China, 2015. Zhonghua Yu Fang Yi Xue Za Zhi (in Chinese). 2019;53(11):1094-7. https://doi.org/10.3760/ cma.j.issn.0253-9624.2019.11.004.

5. Derogar M, Lagergren P. Health-related quality of life among 5-year survivors of esophageal cancer surgery: a prospective population-based study. J Clin Oncol, 2012,30(4), 413-418. https://doi.org/10.1200/JCO.2011.38. 9791.

6. Abnet CC, Arnold M, Wei WQ. Epidemiology of Esophageal Squamous Cell Carcinoma. Gastroenterology, 2018;154(2):360-73. https://doi.org/10.1053/j. gastro.2017.08.023

7. Domper Arnal MJ, Ferrández Arenas Á, Lanas Arbeloa Á. Esophageal cancer: Risk factors, screening and endoscopic treatment in Western and Eastern 
countries. World J Gastroenterol, 2015;21 (26):7933-43. https://doi.org/10.374 8/wjg.v21.i26.7933.

8. Al-Khyatt W, Tufarelli C, Khan R, Iftikhar SY. Selective oestrogen receptor antagonists inhibit oesophageal cancer cell proliferation in vitro. BMC Cancer, 2018;18:121. https://doi.org/10.1186/s12885-018-4030-5.

9. Liu F, Feng H, Guo S, Chen Y, Liu Q, Wu F, et al. Esophageal cancer: should gender be considered as an influential factor for patient safety in drug treatment? J Oncol, 2019;2019:6340567. https://doi.org/10.1155/2019/634 0567.

10. Lin $Y$, Totsuka $Y$, He Y, Kikuchi S, Qiao Y, Ueda J, et al. Epidemiology of esophageal cancer in Japan and China. J Epidemiol, 2013;23(4):233-42 https://doi.org/10.2188/jea.je20120162.

11. Cheung WY, Liu G. Genetic variations in esophageal cancer risk and prognosis. Gastroenterol Clin North Am, 2009 Mar; 38(1):75-91, viii. https:// doi.org/10.1016/j.gtc.2009.01.009

12. Wu C, Hu Z, He Z, Jia W, Wang F, Zhou Y, Liu Z, Zhan Q, Liu Y, Yu D, et al. Genome-wide association study identifies three new susceptibility loci for esophageal squamous-cell carcinoma in Chinese populations. Nat Genet, 2011;43:679-684. https://doi.org/10.1038/ng.849.

13. Wu C, Li D, Jia W, Hu Z, Zhou Y, Yu D, Tong T, Wang M, Lin D, Qiao Y, et al. Genome-wide association study identifies common variants in SLC39A6 associated with length of survival in esophageal squamous-cell carcinoma. Nat Genet, 2013;45:632-638. https://doi.org/10.1038/ng.2638.

14. Gao YB, Chen ZL, Li JG, Hu XD, Shi XJ, Sun ZM, Zhang F, Zhao ZR, Li ZT, Liu ZY, et al. Geneetic landscape of esophageal squamous cell carcinoma. Nat Genet. 2014;46:1097-1102. https://doi.org/10.1038/ng.3 076.

15. Kisely S, Crowe E, Lawrence D. Cancer-related mortality in people with mental illness. JAMA Psychiatry, 2013,70, 209-17. https://doi.org/10.1001/ja mapsychiatry.2013.278.

16. Scott KM, Lim C, Al-Hamzawi A, Alonso J, Bruffaerts R, Caldas-deAlmeida JM, et al. Association of mental disorders with subsequent chronic physical conditions: world mental health surveys from 17 countries. JAMA Psychiatry, 2016,73, 150-158. https://doi.org/10.1001/ja mapsychiatry.2015.2688.

17. Steel Z, Marnane C, Iranpour C, Chey T, Jackson JW, Patel V, et al. The global prevalence of common mental disorders: a systematic review and metaanalysis 1980-2013. Int J Epidemiol, 2014,43(2), 476-493. https://doi.org/10.1 093/ije/dyu038.

18. Park LT, Zarate CA. Depression in the primary care setting. N Engl J Med, 2019,380, 559-568. https://doi.org/10.1056/NEJMcp1712493.

19. Satin JR, Linden W, Phillips MJ. Depression as a predictor of disease progression and mortality in cancer patients: a meta-analysis. Cancer, 2009,115, 5349-5361. https://doi.org/10.1002/cncr.24561.

20. Wang YH, Li JQ, Shi JF, Que JY, Liu JJ, Lappin JM, et al. Depression and anxiety in relation to cancer incidence and mortality: a systematic review and meta-analysis of cohort studies. Mol Psychiat, 2020,25(7), 1487-1499. https://doi.org/10.1038/s41380-019-0595-x.

21. Jia Y, Li F, Liu YF, Zhao JP, Leng MM, Chen L. Depression and cancer risk: a systematic review and meta-analysis. Public Health, 2017,149, 138-148. https://doi.org/10.1016/j.puhe.2017.04.026.

22. Pinquart M, Duberstein PR. Depression and cancer mortality: a metaanalysis. Psychol Med, 2010, 40, 1797-1810. https://doi.org/10.1017/S00332 91709992285

23. Yang YL, Liu L, Wang Y, Wu H, Yang XS, Wang JN, et al. The prevalence of depression and anxiety among Chinese adults with cancer: a systematic review and meta-analysis. BMC Cancer, 2013,13, 393. https://doi.org/10.11 86/1471-2407-13-393.

24. Shen CC, Hu LY, Hu YW, Chang WH, Tang PL, Chen PM, et al. The Risk of Cancer in Patients with Obsessive-Compulsive Disorder: A Nationwide Population-Based Retrospective Cohort Study. Medicine, 2016,95(9), e2989. <https://doi.org/10.1097/MD.0000000000002989.

25. Chen R, Ma SR, Guan CT, Song GH, Ma Q, Xie SH, et al. The National Cohort of Esophageal Cancer-Prospective Cohort Study of Esophageal Cancer and Precancerous Lesions based on High-Risk Population in China (NCEC-HRP): study protocol. BMJ Open, 2019,9(4), e027360. https://doi.org/10.1136/ bmjopen-2018-027360.

26. Kroenke K, Spitzer RL, Williams JBW. The PHQ-9: validity of a brief depression severity measure. J Gen Intern Med, 2001,16, 606-613. https://doi.org/10.104 6/j.1525-1497.2001.016009606.x.
27. Levis B, Benedetti A, Thombs BD. Accuracy of Patient Health Questionnaire9 (PHQ-9) for screening to detect major depression: individual participant data meta-analysis. Br Med J, 2019, 365, 11476. https://doi.org/10.1136/bmj. 11476.

28. American Psychiatric Association. Diagnostic and Statistical Manual of Mental Disorders, 5th Edition: DSM-5. Arlington, VA. 2013.

29. Wang W, Bian Q, Zhao Y, Li X, Wang W, Du J, et al. Reliability and validity of the Chinese version of the Patient Health Questionnaire (PHQ-9) in the general population. General Hospital Psychiatry, 2014, 36(5), 539-544. https://doi.org/10.1016/j.genhosppsych.2014.05.021.

30. Zhu C, Chen Q, Si W, Li Y, Chen G, Zhao Q. Alcohol Use and Depression: A Mendelian Randomization Study From China. Front Genet, 2020;11:585351. https://doi.org/10.3389/fgene.2020.585351.

31. Keyes KM, Allel K, Staudinger UM, Ornstein KA, Calvo E. Alcohol consumption predicts incidence of depressive episodes across 10 years among older adults in 19 countries. Int Rev Neurobiol, 2019;148:1-38. https://doi.org/10.1016/bs.irn.2019.09.001.

32. Luo H, Li J, Zhang Q, Cao P, Ren X, Fang A, et al. Obesity and the onset of depressive symptoms among middle-aged and older adults in China: evidence from the CHARLS. BMC Public Health, 2018;18(1):909. https://doi. org/10.1186/s12889-018-5834-6.

33. Qian J, Li N, Ren X. Obesity and depressive symptoms among Chinese people aged 45 and over. Sci Rep, 2017;7:45637. https://doi.org/10.1038/ srep45637.

34. Ho RC, Niti M, Kua EH, Ng TP. Body mass index, waist circumference, waisthip ratio and depressive symptoms in Chinese elderly: a population-based study. Int J Geriatr Psychiatry, 2008;23:401-408. https://doi.org/10.1002/gps.1 893.

35. Smith M, Zhou M, Whitlock G, Yang G, Offer A, Hui G, et al. Esophageal cancer and body mass index: results from a prospective study of 220,000 men in China and a meta-analysis of published studies. Int J Cancer, 2008; 122(7):1604-10. https://doi.org/10.1002/ijc.23198.

36. Sugawara K, Yamashita H, Okumura Y, Yagi K, Aikou S, Seto Y. Agedependent survival impact of body mass index in patients with oesophageal squamous cell carcinoma. Eur J Surg Oncol, 2020 Oct;46 (10 Pt A):1948-1955. https://doi.org/10.1016/j.ejso.2020.05.012.

37. Liu Q, He H, Yang J, Feng X, Zhao F, Lyu J. Changes in the global burden of depression from 1990 to 2017: Findings from the Global Burden of Disease study. J. Psychiatr. Res, 2020;126:134-140. https://doi.org/10.1016/j. jpsychires.2019.08.002.

38. World Health Organization. Depression and other common mental disorders. 2017

39. World Federation for Mental Health. Occoquan: World Federation for Mental Health. Depression: a global crisis. World Mental Health Day, October. 2012; 10:2012.

40. World Health Organization. The global burden of disease: 2004 update. Geneva Switzerland: World Health Organization; 2008.

41. Chen Y, Bennett D, Clarke R, Guo Y, Yu C, Bian Z, et al. Patterns and correlates of major depression in Chinese adults: a cross-sectional study of 0.5 million men and women. Psychol Med, 2017,47(5), 958-970. https://doi. org/10.1017/S0033291716002889.

42. Jin Lu, Xiufeng Xu, Yueqin Huang, Tao Li, Chao Ma, Guangming Xu, et al. Prevalence of depressive disorders and treatment in China: a cross-sectional epidemiological study. Lancet Psychiatry. 2021 Sep 21;\$22150366(21)00251-0. https://doi.org/10.1016/S2215-0366(21)00251-0.

43. Ahn H, Bae J, Ahn H, Hwang I. Risk of cancer among patients with depressive disorder: a meta-analysis and implications. Psychooncology. 2016;25:1393-9. https://doi.org/10.1002/pon.4084.

44. Armaiz-Pena GN, Lutgendorf SK, Cole SW, Sood AK. Neuroendocrine modulation of cancer progression. Brain, Behavior, and Immunity, 2009,23, 10-15. https://doi.org/10.1016/j.bbi.2008.06.007.

45. Kessler, RC. The effects of stressful life events on depression. Annu Rev Psychol, 1997,48, 191-214. https://doi.org/10.1146/annurev.psych.48.1.191.

46. Spiegel D, Giese-Davis J. Depression and cancer: mechanisms and disease progression. Biol Psychiatry. 2003:54:269-82. https://doi.org/10.1016/ s0006-3223(03)00566-3.

47. Strine TW, Mokdad AH, Dube SR, Balluz LS, Gonzalez O, Berry JT, et al. The association of depression and anxiety with obesity and unhealthy behaviors among community-dwelling US adults. Gen Hosp Psychiatry, 2008,30, 12737. https://doi.org/10.1016/j.genhosppsych.2007.12.008. 
48. Watts M. Understanding the coexistence of alcohol misuse and depression. Br J Nurs, 2008,17(11), 696-699. https://doi.org/10.12968/bjon.2008.17.11.2 9614.

49. Tonello L, Oliveira-Silva I, Medeiros AR, Donato ANA, Schuch FB, Donath L, et al. Prediction of Depression Scores From Aerobic Fitness, Body Fatness, Physical Activity, and Vagal Indices in Non-exercising, Female Workers. Front Psychiatry. 2019;10:192. https://doi.org/10.3389/fpsyt.2019.00192.

50. Martin-Rodriguez E, Guillen-Grima F, Aubá E, Martí A, Brugos-Larumbe A. Relationship between body mass index and depression in women: A 7-year prospective cohort study The APNA study. Eur Psychiatry. 2016;32:55-60. https://doi.org/10.1016/j.eurpsy.2015.11.003.

\section{Publisher's Note}

Springer Nature remains neutral with regard to jurisdictional claims in published maps and institutional affiliations.

Ready to submit your research? Choose BMC and benefit from:

- fast, convenient online submission

- thorough peer review by experienced researchers in your field

- rapid publication on acceptance

- support for research data, including large and complex data types

- gold Open Access which fosters wider collaboration and increased citations

- maximum visibility for your research: over $100 \mathrm{M}$ website views per year

At $\mathrm{BMC}$, research is always in progress.

Learn more biomedcentral.com/submissions 